\title{
Innovation in wound management with disposable, portable, cost-effective and non-powered NPWT device: Experience in general surgery
}

\author{
Bashir $\mathrm{Y}^{* 1}$, Ulain $\mathrm{Q}^{1}$, O'Brien $\mathrm{G}^{1}$, Chonchubhair $\mathrm{H}^{2}$, Al-Sahaf $\mathrm{O}^{1}$ \\ ${ }^{1}$ Naas General Hospital, County Kildare, Ireland \\ ${ }^{2}$ Professorial Surgical Unit, Department of Surgery, The University of Dublin trinity College, Tallaght Hospital, Dublin, Ireland
}

Received: November 17, 2016

DOI: $10.5430 /$ css.v3n1p22
Accepted: January 11, 2017

Online Published: January 17, 2017

URL: http://dx.doi.org/10.5430/css.v3n1p22

\begin{abstract}
Wound management is vital part of surgery. We used a non-powered, disposable, portable Negative Pressure Wound Therapy dressing (NPWT) ("Nanova ${ }^{\mathrm{TM}}$ ", $\mathrm{KCI}^{\mathrm{TM}}$ ) on different types of surgical wounds treated in one Secondary Care Hospital in Ireland. It is easy to use and is self-operated by patients. It was trialled on three patients, was well tolerated, resulting in early mobility and return to daily activities, along with rapid recovery. There was no non-compliance or adverse effects to surrounding skin. The recovery time ranged from 2-3 weeks. The use of this device positively affected the clinical outcome and resulted in early discharge from hospital, quicker recovery and early return to daily activities.
\end{abstract}

Key Words: Case series, Negative Pressure Wound Therapy, Wounds, Wound Management

\section{INTRODUCTION}

As surgeons we encounter wounds on a daily basis. For complex wounds we use NPWT, they are complex and often requires hospital admission. ${ }^{[1]}$ We want to share our experience of new, non-powered and disposable NPWT (Nanova ${ }^{\mathrm{TM}}$ ), which allow early discharge from hospital to reduce cost and also decrease risks of nosocomial infection. The average cost of Vac dressing is around $500 €$ per week for a patient. The machine has to be rented, while dressings are also costly. Meanwhile Nanova ${ }^{\mathrm{TM}}$ cost around $135 €$ per week for a patient for first week, then 2 dressings per week at around $19 € /$ dressings are required making it at least $66 \%$ cheaper than the normal Vac dressings (The cost shown is the price at which the products are supplied to Naas General Hospital. There Might be a slight difference in prices between different buyers depending on quantity of purchase). Aim of our case series was to see effectiveness of "Nanova ${ }^{\mathrm{TM}}$ " on different type of wounds encountered in our experience in General Surgical practise. The selection of patients was done based on clinical judgement and after discussion with Tissue Viability Nurse. All these wounds have cavities smaller than $5 \mathrm{~cm}$ and were large enough to need NPWT, so decision was made to use "Nanova ${ }^{\mathrm{TM}}$ " and we have very positive experience to share with everyone about these devices.

\section{CASE Series}

Case 1: An 87-year-old female presented with a large haematoma on her right leg which was evacuated, resulting in a substantial cavity of $10 \mathrm{~cm} \times 10 \mathrm{~cm}$ width and $0.9 \mathrm{~cm}$ depth. Nanova ${ }^{\mathrm{TM}}$ dressing was applied and the patient was discharged the same day. The dressing was changed twice weekly with once-weekly follow up in the wound clinic. The

*Correspondence: Bashir Y; Email: yasirb1@outlook.com; Address: Naas General Hospital, County Kildare, Ireland. 
wound healed completely within 3 weeks (see Figure 1).

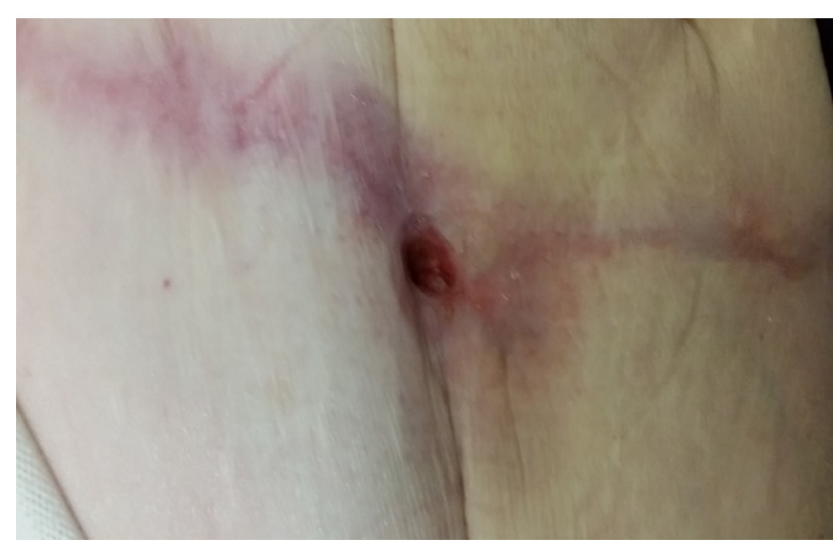

Figure 1. Patient 1 at 2 weeks of Nanova therapy

Case 2: A 25-year-old male had I\&D for an abscess in the lumbar region. There was a $7 \mathrm{~cm}$ length, $4 \mathrm{~cm}$ deep cavity. Nanova ${ }^{\mathrm{TM}}$ was applied on the $2^{\text {nd }}$ post-op day and he was sent home the same day. The dressing was changed twice weekly and the wound healed within two weeks (see Figure 2).
Case 3: A 57-year-old female who had a laparotomy for bowel resection, and post operatively had superficial wound dehiscence. The wound was $5 \mathrm{~cm}$ long and $3.2 \mathrm{~cm}$ deep. Nanova $^{\mathrm{TM}}$ dressing was applied and the patient was discharged the same day. She had bi-weekly dressing changes and had weekly follow-up in wound clinic. The wound healed within three weeks (see Figures 3-4).

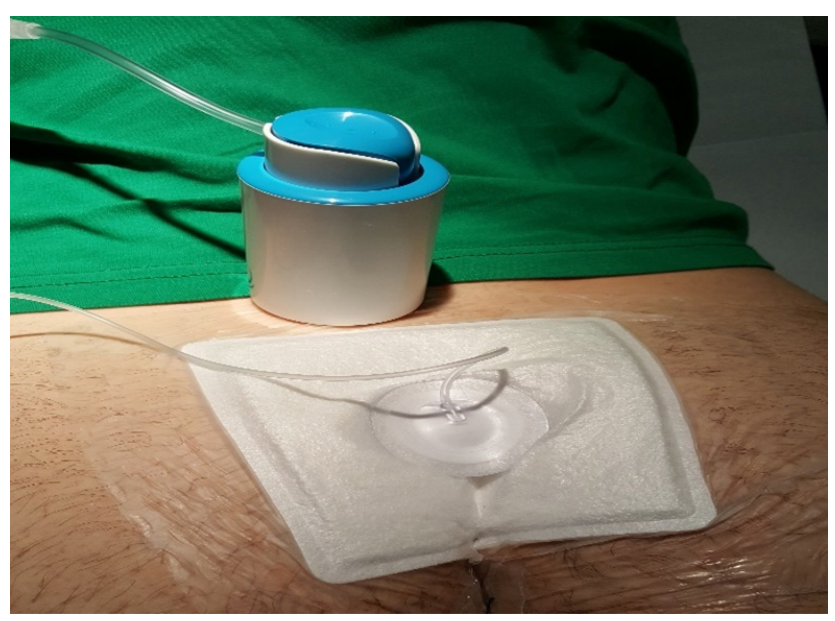

Figure 2. Patient 2 at commencement of Nanova therapy

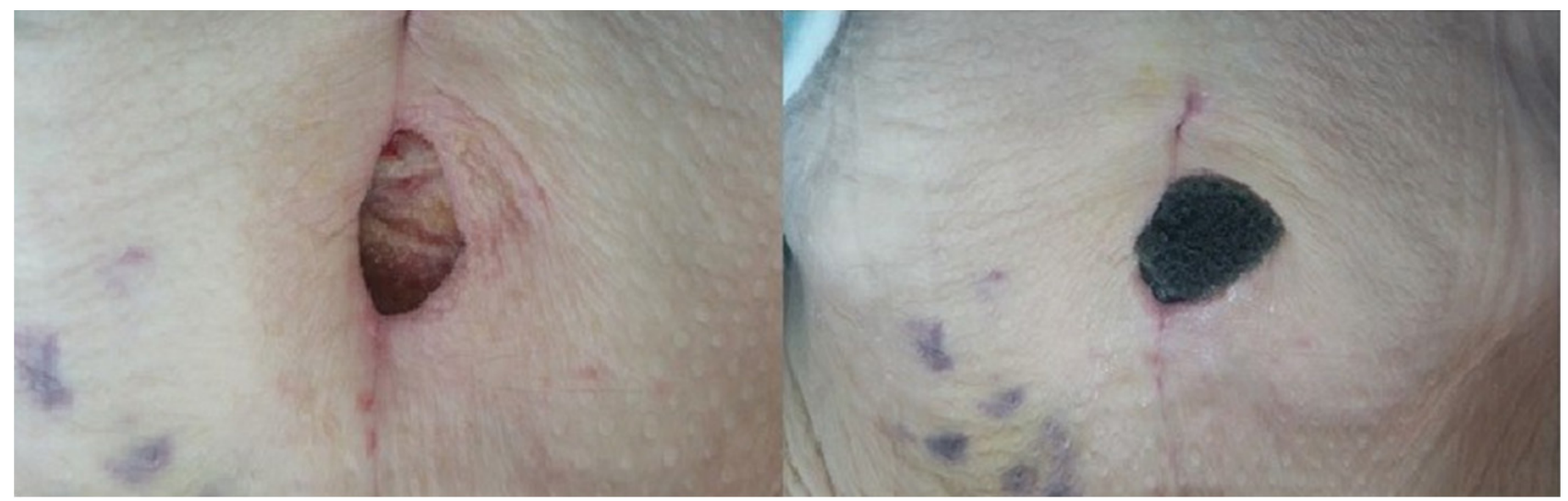

Figure 3. Wound of patient 3 at 1 week of Nanova ${ }^{\mathrm{TM}}$ use and preparation for re-application of Nanova ${ }^{\mathrm{TM}}$

\section{Discussion}

The history of wound management starts with the history of mankind, first written medical records dates from about 2500 BC. Plants with antimicrobial effects were used for wound treatment for thousands of years. ${ }^{[2]}$ In 1865 , Dr. Joseph Lister started treating wounds with dressings soaked in carbonic acid and germ theory of infection was understood. ${ }^{[3]}$ Wound dressings were historically used, but later it was found that wounds generating moderate to high levels of exudate required absorbent dressings. Foam and calcium alginate both have excellent absorbency. ${ }^{[4]}$ Raffl was the first one to describe a practical way of continuous negative suction ${ }^{[5]}$ and later its benefits were proven. ${ }^{[6]}$ NPWT proved to be better than moist gauze dressings in diabetic feet, ${ }^{[7]}$ effective in the treatment of chronic leg ulcers ${ }^{[8]}$ and also showed better graft take $p<.05 .{ }^{[9]}$

Previously NPWT were always applied during hospital admission. ${ }^{[1]}$ With better primary care facilities, they can be managed at home. There is a need to make these devices portable and easy to manage in order to ensure early return to routine. Many companies invented devices to facilitate early discharge from hospital, and this disposable device by KCI ${ }^{\mathrm{TM}}$ "Nanova"TM" is the result of a similar effort. 

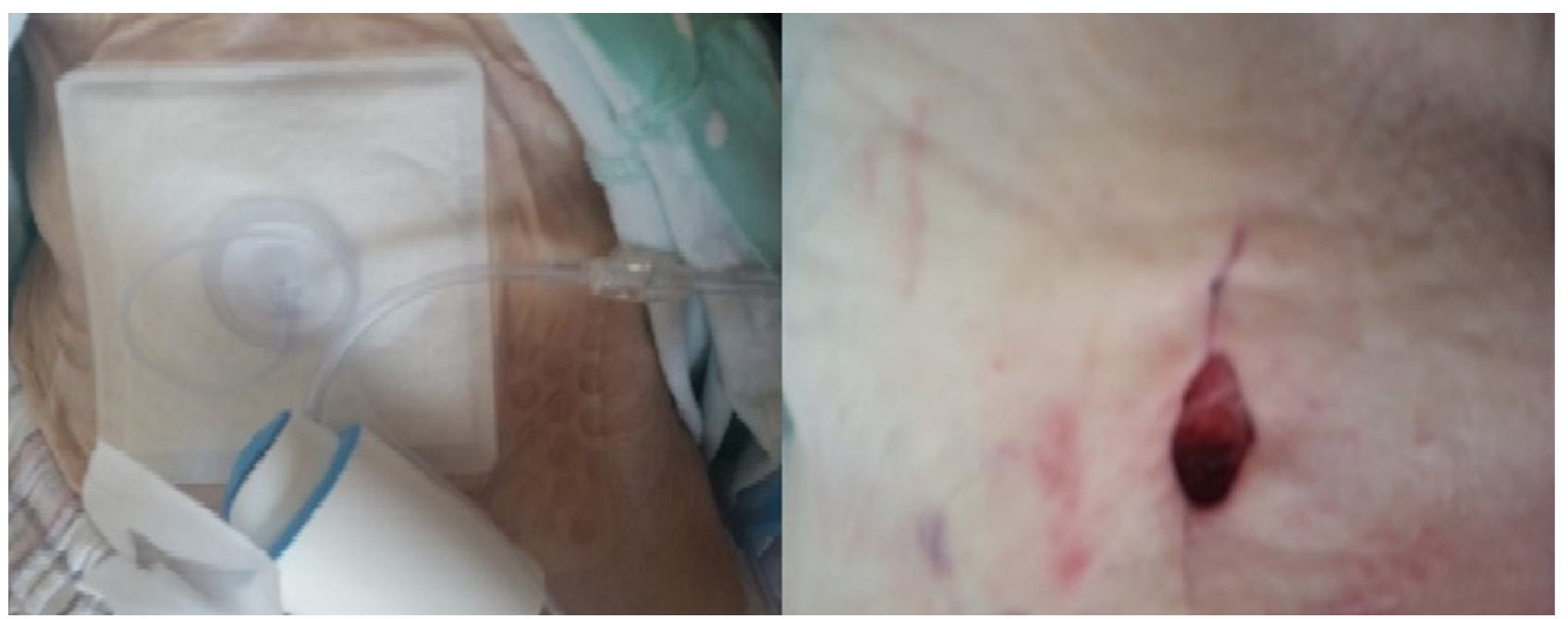

Figure 4. Dressing applied to patient 3 and wound at 2 weeks on the right

It is a highly effective and reliable device, portable and costeffective. These are single patient use devices with manual priming mechanism and 1-3 compressions of pump delivers negative pressure of $125 \mathrm{mmHg}$. This unit with multiple dressing change can be used for 30 days. The dressing consists of a non-adherent silicone wound contact layer. The border is a hybrid material that combines silicone and acrylic adhesives, that provides an effective seal.

Unfortunately, there are limitations to the use of this device. The device cannot be used on wounds deeper than $5 \mathrm{~cm}$. Also, they don't include an alarm to indicate that there

\section{REFERENCES}

[1] Dowsett C. Breaking the cycle of hard-to-heal wounds: balancing cost and care. Wounds International. 2015; 6(2): 17-21.

[2] Forrest RD. Early history of wound treatment. Journal of the Royal Society of Medicine. 1982; 75(3): 198-205. PMid: 7040656.

[3] Broughton G, Janis JE, Attinger CE. A brief history of wound care. Plastic and reconstructive surgery. 2006; $117(7$ Suppl): 6S-11S. PMid: 16799371. https://doi.org/10.1097/01.prs.00002 25429.76355.dd

[4] Ovington LG. Advances in wound dressings. Clinics in dermatology. 2007; 25(1): 33-8. PMid: 17276199. https://doi.org/10.101 6/j.clindermatol.2006.09.003

[5] Raffl AB. The use of negative pressure under skin flaps after radical mastectomy. Annals of surgery. 1952; 136(6): 1048. PMid: 12986694. https ://doi .org/10.1097/00000658-195212000 $-00022$ is malfunction, like the powered versions of NPWT. Also, available literature on disposable negative suction dressings is sparse.

In conclusion, results of our case series indicate that this device is easy to use, convenient, cost-effective and resulted in adequate wound healing, early discharged and early return to baseline for patients. A randomized controlled trial (RCT) comparing these devices with conventional NPWTs in areas of efficacy and cost-effectiveness is warranted.

\section{CONFLicts OF InTEREST Disclosure}

The authors declare they have no conflict of interest.
[6] Silvis RS, Potter LE, Robinson DW, et al. The use of continuous suction negative pressure instead of pressure dressing. Annals of surgery. 1955; 142(2): 252-6. PMid: 13239059. https : //doi.org/10.1097/00000658-195508000-00011

[7] Eginton MT, Brown KR, Seabrook GR, et al. A prospective randomized evaluation of negative-pressure wound dressings for diabetic foot wounds. Annals of vascular surgery. 2003; 17(6): 645-9. PMid: 14534844. https://doi.org/10.1007/s10016-003-0065-3

[8] Vuerstaek JD, Vainas T, Wuite J, et al. State-of-the-art treatment of chronic leg ulcers: A randomized controlled trial comparing vacuumassisted closure (V.A.C.) with modern wound dressings. Journal of vascular surgery. 2006; 44(5): 1029-37; discussion 38. PMid: 17000077. https://doi.org/10.1016/j.jvs.2006.07.030

[9] Moisidis E, Heath T, Boorer C, et al. A prospective, blinded, randomized, controlled clinical trial of topical negative pressure use in skin grafting. Plastic and reconstructive surgery. 2004; 114(4): 917-22. PMid: 15468399. https://doi.org/10.1097/01.PRS $.0000133168 .57199 . \mathrm{E} 1$ 